University of Nebraska - Lincoln

DigitalCommons@University of Nebraska - Lincoln

Faculty Publications from the Harold W. Manter Laboratory of Parasitology

6-1998

Echinocephalus janzeni n. sp. (Nematoda: Gnathostomatidae) in Himantura pacifica (Chondrichthyes: Myliobatiformes) from the Pacific Coast of Costa Rica and Mexico, with Historical Biogeographic Analysis of the Genus

\author{
Eric P. Hoberg \\ United States Department of Agriculture \\ Daniel R. Brooks \\ University of Toronto,dnlbrooks@gmail.com \\ Helena Molina Ureña \\ Universidad de Costa Rica \\ Eric Erbe \\ United States Department of Agriculture
}

Follow this and additional works at: https://digitalcommons.unl.edu/parasitologyfacpubs

Part of the Parasitology Commons

Hoberg, Eric P.; Brooks, Daniel R.; Molina Ureña, Helena; and Erbe, Eric, "Echinocephalus janzeni n. sp. (Nematoda: Gnathostomatidae) in Himantura pacifica (Chondrichthyes: Myliobatiformes) from the Pacific Coast of Costa Rica and Mexico, with Historical Biogeographic Analysis of the Genus" (1998). Faculty Publications from the Harold W. Manter Laboratory of Parasitology. 276.

https://digitalcommons.unl.edu/parasitologyfacpubs/276

This Article is brought to you for free and open access by the Parasitology, Harold W. Manter Laboratory of at DigitalCommons@University of Nebraska - Lincoln. It has been accepted for inclusion in Faculty Publications from the Harold W. Manter Laboratory of Parasitology by an authorized administrator of DigitalCommons@University of Nebraska - Lincoln. 


\title{
ECHINOCEPHALUS JANZENI N. SP. (NEMATODA: GNATHOSTOMATIDAE) IN HIMANTURA PACIFICA (CHONDRICHTHYES: MYLIOBATIFORMES) FROM THE PACIFIC COAST OF COSTA RICA AND MEXICO, WITH HISTORICAL BIOGEOGRAPHIC ANALYSIS OF THE GENUS
}

\author{
Eric P. Hoberg, Daniel R. Brooks*, Helena Molina-Ureña†, and Eric Erbeł \\ United States Department of Agriculture, Agricultural Research Service, Biosystematics and National Parasite Collection Unit, BARC East No. \\ 1180, 10300 Baltimore Avenue, Beltsville, Maryland 20705
}

\begin{abstract}
Echinocephalus janzeni $\mathrm{n}$. sp. in the stingray, Himantura pacifica, is described from the eastern Pacific Ocean off the coasts of Costa Rica and southern Mexico. On the basis of the presence of 6 postanal caudal papillae, and modified annules anterior to the caudal alae in males, E. janzeni is most similar to Echinocephalus daileyi and Echinocephalus diazi. Specimens of $E$. janzeni are distinguished from those of $E$. daileyi by bilobed caudal alae and long cervical sacs that extend up to $65 \%$ of the length of the esophagus; $E$. janzeni is differentiated from $E$. diazi by the number of rows of cephalic spines (30-38 vs. 2627), arrangement of the postanal caudal papillae, 3 rather than 2 preanal papillae, relative position and distance between the anus and vulva $(395-460 \mu \mathrm{m}$ vs. $70 \mu \mathrm{m})$, the digitiform female tail with a terminal cuticular fold, and the length of the female tail $(450-480 \mu \mathrm{m}$ vs. $270 \mu \mathrm{m})$. Cladistic analysis of the 10 Echinocephalus spp. resulted in a single most parsimonious tree (consistency index $=0.893$ ) and placed $E$. janzeni in a highly derived subclade where $E$. dailey is the sister species of $E$. diazi + E. janzeni. Historical biogeographic analysis of hosts and parasites provides support for origins in the Pacific rather than the Atlantic for the potamotrygonid stingrays.
\end{abstract}

Echinocephalus Molin, 1858, contains 9 species of distinctive gnathostomatids that are limited in host distribution primarily to marine and freshwater stingrays (e.g., Troncy, 1969; Deardorff et al., 1981; Beveridge, 1985). Interest in the systematics and biology of species of Echinocephalus has had both theoretical and practical components. This group has figured prominently in the development of hypotheses for the origins and biogeographic history of freshwater stingrays, Potamotrygonidae, of the neotropics (Brooks et al., 1981; Brooks and Deardorff, 1988; Brooks and McLennan, 1993). Additionally, because life cycles for species of Echinocephalus involve mollusks, e.g., oysters, Crassostrea gigas (Thunberg), and abalone, Haliotis corrugata Gray, as intermediate hosts (Millemann, 1951, 1963; Ko, 1975), the possibility of accidental infection in humans is apparent. In this regard, Echinocephalus sinensis has been demonstrated to be invasive and to undergo visceral migrations in a number of mammalian hosts (Ko et al., 1975; Ko, 1976). Thus, like other gnathostomatids such as Gnathostoma spinigerum Owen, 1836, species of Echinocephalus can pose a health risk for humans (Miyazaki, 1960; Brooks and Deardorff, 1988).

Herein we describe a previously unrecognized species of Echinocephalus found in Himantura pacifica (Beebe and Tee Van) from the eastern Pacific Ocean. A new phylogenetic and historical biogeographic analysis of the genus is applied to an evaluation of the origins of freshwater stingrays of South America (see Brooks et al. 1981).

\section{MATERIALS AND METHODS}

Live nematodes were removed from the spiral intestine of a ray collected by beach seine at Guanacaste, Costa Rica, in 1992. Worms were

Received 21 August 1997; revised 2 December 1997; accepted 2 December 1997.

* Department of Zoology, University of Toronto, Toronto, Ontario, Canada M5S $1 \mathrm{~A} 1$.

† Escuela de Biologia, Universidad de Costa Rica, San José, Costa Rica.

$¥$ United States Department of Agriculture, Agricultural Research Service, Nematology Laboratory, Electron Microscopy Unit, BARC East No. 117B, 10300 Baltimore Avenue, Beltsville, Maryland 20705. washed in saline, simultaneously killed and fixed in glacial acetic acid, and then transferred and stored in $70 \%$ ethanol with 5\% glycerine prior to examination. A second ray caught by longline in waters adjacent to El Paredon, Mexico, was purchased from local fishermen in 1997. In this instance, the entire spiral intestine was fixed in 5\% formalin; nematodes were collected in the laboratory. These specimens fixed in situ were determined to be conspecific with those from Costa Rica, but because of fixation artifacts and contraction of the cephalic and caudal regions, they were not included in the type series or description.

The description was based on 5 complete males and 3 gravid females. Specimens were cleared in phenol-alcohol and examined as whole mounts. A male specimen was examined by scanning electron microscopy (SEM) to define cephalic structures with a method not previously applied to studies of zooparasitic nematodes. In the description, measurements are in micrometers unless specified otherwise; where sample size ( $\mathrm{n}$ ) is $\geq 5$, the range is followed by the mean \pm 1 SD. Type specimens and part of the vouchers were deposited in the U.S. National Parasite Collection, Biosystematics and National Parasite Collection Unit, U.S.D.A., Agricultural Research Service, Beltsville, Maryland (USNPC); voucher specimens were also deposited in the Coleccion Nacional de Helmintos (CNHe) of the Instituto de Biología, Universidad Nacional Autonoma de Mexico (UNAM).

\section{Scanning electron microscopy}

A male specimen, stored in $70 \%$ ethanol, was rehydrated stepwise to $100 \%$ water and transferred to a modified Oxford specimen cryoholder. Modification consisted of drilling a 1-mm hole in the holder so the anterior of a bisected specimen could be inserted vertically to fully expose the cephalic extremity. The specimen was transferred to the holder, oriented, excess water removed by wicking with filter paper and then plunge-frozen in liquid nitrogen $\left(\mathrm{LN}_{2}\right)$ at $-196 \mathrm{C}$. The holder was transferred to the precooled stage of an Oxford CT-1500 HF Cryotrans System that was interfaced to a Hitachi S-4100 field emission SEM. The temperature was raised to $-90 \mathrm{C}$ for $15 \mathrm{~min}$ to sublime any residual surface water then recooled to below $-100 \mathrm{C}$, and the specimen was coated with a thin layer of platinum with a magnetron sputter coater. The coated specimen was then transferred to the cold stage $(<-160 \mathrm{C})$ of the low temperature (LT) SEM and observed and photographed at an accelerating voltage of $2 \mathrm{kV}$. After completion of initial observations, the specimen was thawed, reoriented at a different angle, and refrozen (as specified above) for further observations. Micrographs were recorded on Polaroid type $55 \mathrm{P} / \mathrm{N}$ film. To record a pair of stereo micrographs having parallax information required for 3-dimensional viewing, the stage was tilted 6 degrees between the first and second micrographs.

Stereoscopic images are presented in Figures 9-12. A 3-dimensional (stereo) image can be perceived by placing a stereo viewer on the fig- 
TABLE I. Character matrix for phylogenetic analysis of Echinocephalus.

\begin{tabular}{|c|c|c|c|c|c|c|c|c|c|c|c|c|c|c|c|}
\hline \multirow[b]{2}{*}{ Taxa } & \multicolumn{15}{|c|}{ Character } \\
\hline & 1 & 2 & 3 & 4 & 5 & 6 & 7 & 8 & 9 & 101 & & 121 & & 141 & \\
\hline Gnathostomatidae* & 0 & 0 & 0 & 0 & 0 & 0 & 0 & 0 & 0 & 00 & $0 \quad 0$ & 0 & 0 & & 0 \\
\hline E. diazi & 1 & 1 & 0 & 0 & 1 & 0 & 1 & 4 & 2 & $\begin{array}{ll}0 & 1\end{array}$ & 10 & 0 & 1 & 11 & 1 \\
\hline E. sinensis & 1 & 0 & 1 & 0 & 0 & 0 & 1 & 4 & 0 & 00 & $\begin{array}{ll}0 & 1\end{array}$ & 12 & 2 & $\begin{array}{lll}0 & 1\end{array}$ & 1 \\
\hline E. pseudouncinatus & 1 & 0 & 1 & 0 & 0 & 0 & 1 & 3 & 3 & $\begin{array}{ll}0 & 0\end{array}$ & $\begin{array}{ll}0 & 1\end{array}$ & 1 & 1 & $\begin{array}{ll}0 & 1\end{array}$ & 1 \\
\hline E. daileyi & 1 & 0 & 0 & 1 & 0 & 0 & 1 & 5 & 2 & $\begin{array}{ll}0 & 1\end{array}$ & 10 & 0 & 1 & 0 & 1 \\
\hline E. spinosissimus & 1 & 0 & $?$ & 0 & 0 & 1 & 1 & 6 & 1 & 00 & $0 \quad 0$ & 0 & 1 & 0 & 1 \\
\hline E. overstreeti & 1 & 0 & 1 & 1 & 0 & 0 & 1 & 6 & 3 & 10 & $\begin{array}{ll}0 & 0\end{array}$ & 0 & 1 & 0 & 1 \\
\hline E. janzeni n. sp. & 1 & 0 & 0 & 0 & 1 & 0 & 1 & 5 & 2 & $\begin{array}{ll}0 & 1\end{array}$ & 10 & 0 & 3 & 11 & \\
\hline E. uncinatus & 1 & 0 & 1 & 0 & 0 & 1 & 1 & 6 & 1 & 00 & $0 \quad 0$ & 0 & 1 & 0 & 1 \\
\hline E. multidentatus & 0 & 0 & 0 & 0 & 0 & 0 & 2 & 2 & 1 & 00 & $0 ?$ & $?$ & 0 & 0 & 1 \\
\hline E. southwelli & 0 & 0 & 0 & 0 & 0 & 0 & 0 & 1 & 0 & 00 & $0 ?$ & $?$ & 0 & 0 & 1 \\
\hline
\end{tabular}

* Gnathostomatidae outgroups.

ures so the left and right lenses are aligned above the left and right images, respectively. Alternatively, stereopsis (3-dimensional viewing) can be achieved without a viewer by entraining the left and right eyes on the left and right figures, respectively. When this is properly accomplished, 3 figures will be perceived; the center image will be in stereo. Stereo images are considered to provide an exceptional depth of field, detail and enhanced resolution that cannot be otherwise attained in 2dimensional figures.

\section{Specimens examined}

The following Echinocephalus species from the USNPC and from the Museum National d'Histoire Naturelle, Paris (MNHN) were examined for comparative purposes: Echinocephalus daileyi Deardorff, Brooks, and Thorson, 1981 (types, USNPC 76094, 76095, 76096); E. diazi Troncy, 1969 (paratypes, MNHN N503), male tails were not available; E. overstreeti Brooks and Deardorff, 1988 (types, USNPC 77382, 77383, 77384); E. pseudouncinatus Millemann, 1951 (types, USNPC 57451, 57452); E. sinensis Ko, 1975 (types, USNPC 73657-73659); and E. uncinatus Molin, 1858 (MNHN N0439), redescribed by Beveridge (1985). Other gnathostomatids examined included Tanqua tiara (von Linstow, 1879) (vouchers, USNPC 63246) and G. spinigerum (vouchers, USNPC 50699).

\section{Phylogenetic analysis}

Phylogenetic analysis (Hennig, 1950, 1966; Wiley et al., 1991) of species of Echinocephalus was based on characters derived from comparative morphology. Morphological attributes included those evaluated previously (Baylis and Lane, 1920; Deardorff et al., 1981; Deardorff and Ko, 1983; Brooks and Deardorff, 1988) with new interpretations and the addition of several new characters. Characters were polarized on the basis of taxonomic (reference to other gnathostomatids) or functional outgroup criteria (char. 13) (Watrous and Wheeler, 1981; Maddison et al., 1984; Wiley et al., 1991). Descriptions for 15 binary and multistate characters are presented following the taxonomic section and in a numerical matrix (Table I). Analysis was conducted with PAUP 3.1.1 (Swofford, 1993) with the following options: transformations unordered, BRANCH AND BOUND search mode, optimization by ACCTRAN. Results are shown as a phylogenetic tree with associated statistics, including the consistency index (CI) and rescaled consistency index (RC) (according to Swofford, 1993). Characters are mapped di- rectly onto the tree for evaluation. The resulting tree forms the basis for discussion of the historical biogeography of hosts and parasites.

\section{DESCRIPTION}

Echinocephalus janzeni n. sp.

(Figs. 1-18)

General description: Based on 5 complete males and 3 females. Body with inconspicuous annules, unarmed, greatest width in posterior one-third. Pseudolabia oriented laterally, equal in size, wider than long, each with 2 lateral double papillae, 1 median amphid; mouth elongate dorsoventrally. Pseudolabia trilobed; internally with 3 cuticularized toothlike projections disposed medially and laterally; internal pulp pedunculate, trilobed. Dentigerous ridges present. Posterolateral margins of pseudolabia serrated, ctenidialike. Preesophageal cuticularized serrations present. Cuticular collar present. Interlabia complex, large, triangular, thornlike, weakly serrated; divergent paired fields of spines extend anterolaterally from each interlabium, terminating in paired, thornlike processes. Cephalic bulb armed with uncinate spines in evenly spaced, nonoverlapping, transverse rows; some rows discontinuous; largest spines posterior. Ballonets 4 in number. Cervical sacs extend from ballonets to near two-thirds length of esophagus. Esophagus 12$19 \%$ of total body length; divided in anterior fifth into anterior muscular and posterior glandular sections.

Male: Body 13.9-33.6 mm long, 415-700 in maximum width; ratio of maximum width to total length, 1:33-48. Pseudolabia 104-143 (125 $\pm 16.73)$ long, $195-260(234 \pm 29.59)$ wide. Cephalic bulb $338-470$

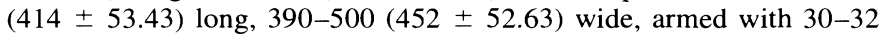
rows of cephalic spines laterally, 33-37 rows dorsoventrally; length of spines $(\mathrm{n}=15) 3-7(5 \pm 1.13)$ on anterior of bulb, $(\mathrm{n}=15) 7-10(8$ $\pm 0.70)$ in midregion, $(\mathrm{n}=15) 8-10(10 \pm 0.59)$ in posterior. Nerve ring 520-660 (623 \pm 588.27), cervical papillae 675-1,020 (871 \pm $140.24)$, excretory pore 675-1,030 (882 \pm 144.51$)$ from anterior extremity. Cervical sacs $(n=18) 1,475-2,775(2,236 \pm 396.56)$ long, 55-110 (78 \pm 17.68$)$ in maximum width at base. Esophagus $12-19 \%$ of body length, 2,626-4,160 (3,342 \pm 674.5) long, 310-400 (359 \pm 32.86 ) wide at base; muscular region 390-546; glandular region 2,2053,614 ; ratio of glandular to muscular regions $1: 0.15-0.17$. Spicules similar, subequal, $5-10 \%$ of total body length; left spicule $1,350-2,000$ $(1,738 \pm 278)$ long, $21-30(24.60 \pm 4.62)$ wide near capitulum; right spicule $1,175-1,685(1,460 \pm 229.24)$; ratio of length left to right spicule, 1:0.81-0.87. Gubernaculum V-shaped in dorsoventral view; 117$185(151 \pm 29.90)$ long in lateral view. Caudal alae bilobate; anterior lobes $(\mathrm{n}=10) \quad 169-250(199 \pm 35.60)$, posterior lobes $375-525(450$ \pm 47.65 ). Alae with 9 pairs of caudal papillae; 3 preanal, with first pair adjacent to cloaca minuscule, second and third pairs large, pedunculate; 6 postanal of unequal length, first pair anterior to caudal extremity minuscule, second and third pairs inconspicuous grouped together, fourth pair medial and near level of lateral and pedunculate fifth pair, sixth pair posterolateral to anus. Preanal organ medioventral, granular in appearance. Modified annules disposed ventrally extending 1,100-1,391 anteriad from anterior edge of caudal alae. Phasmids, paired, located laterally between postanal papillae $2 / 3$ and 4 . Tail conical, 260-310 $(277 \pm 19.7)$ long.

Female: Body $22.9-26.4 \mathrm{~mm}$ long, 535-850 in maximum width; ratio maximum width to total length, 1:31-45. Pseudolabia 125-156 long, 255-269 wide. Cephalic bulb 385-400 long, 480-575; armed with 31-34 rows of cephalic spines laterally, 37-38 rows dorsoventrally; length of spines $(n=15) 5-8(7 \pm 0.95)$ on anterior of bulb, $(n=15)$ 8-10 $(9 \pm 1.05)$ in midregion, $(\mathrm{n}=15) 8-11(9 \pm 1.16)$ in posterior. Nerve ring $525-575$, cervical papillae $700-765$, excretory pore 695 775 from anterior extremity. Cervical sacs $(\mathrm{n}=10) 2,650-3,175(3,011$ $\pm 168.59)$ long, 55-105 (79 \pm 15.74$)$ in maximum width. Esophagus

FIGURES 1-4. Echinocephalus janzeni n. sp., cephalic and caudal structures; scale bars in micrometers. 1. Cephalic and cervical zone in holotype male, ventral view; note the relative lengths of the muscular and glandular esophagus, and the cervical sacs. 2 . Cephalic bulb in holotype male, dorsal view; note the number of rows and disposition of cephalic spines, and the position of the prominent ventral interlabium. 3. Labial structure in allotype female, right lateral view; note tripartite structure of pseudolabium, dentigerous ridges, double cephalic papillae, prominent amphid, and thornlike interlabia with serrated edge. 4. Tail in allotype female; note digitate form, with terminal cuticular fold and relative positions of the anus and vulva (shown is a portion of the vagina vera but not the complete female genital tract). 


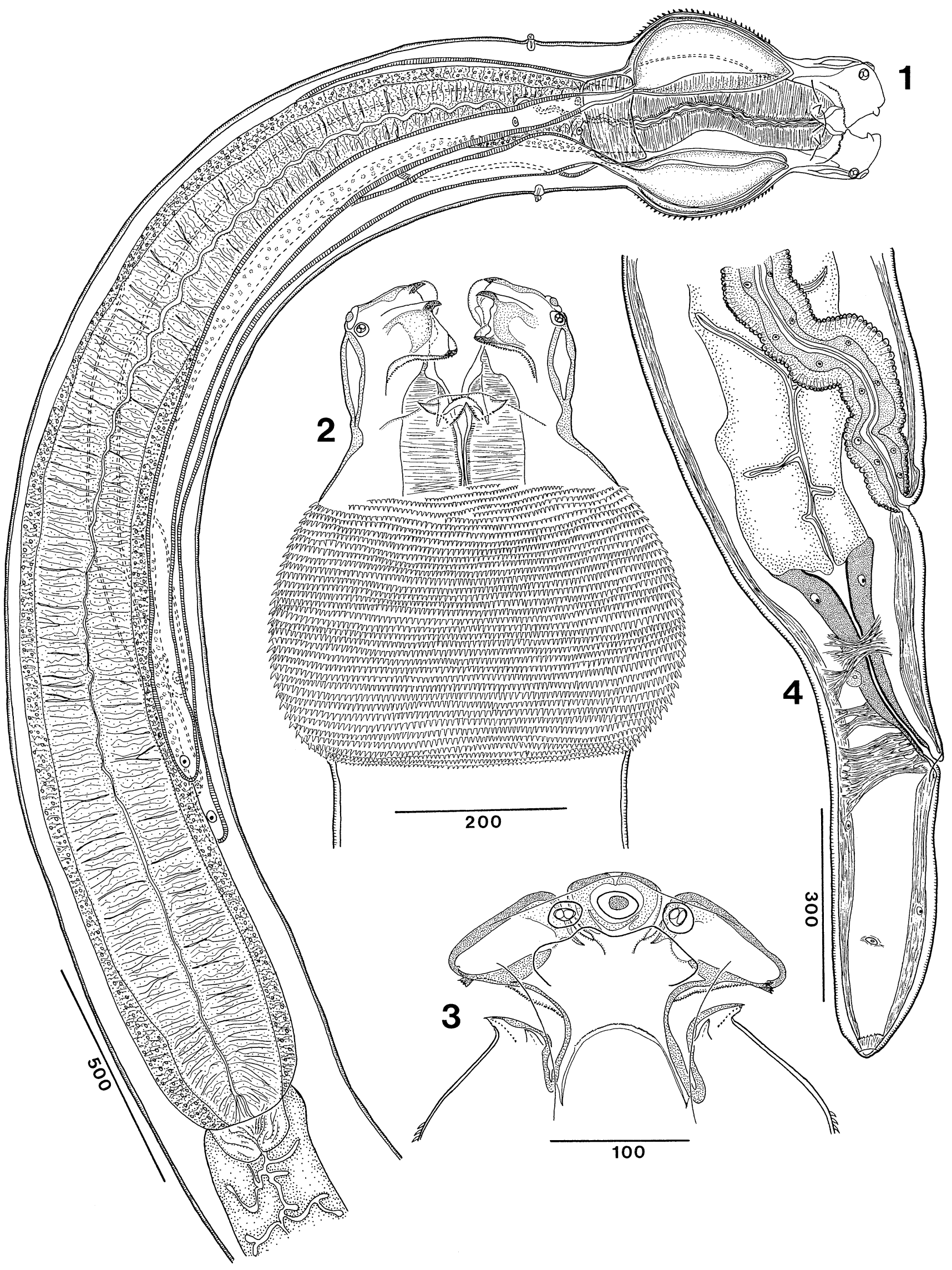




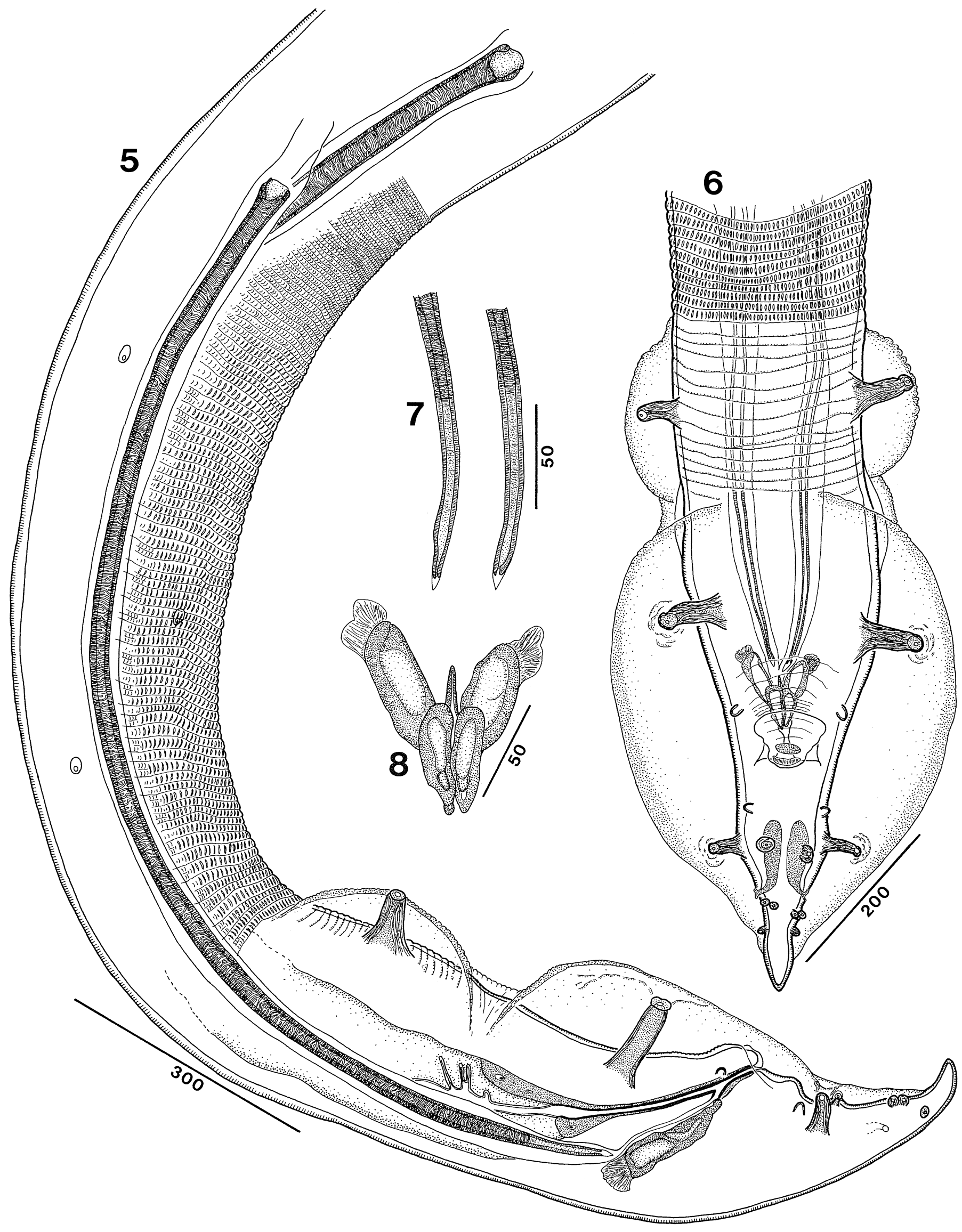



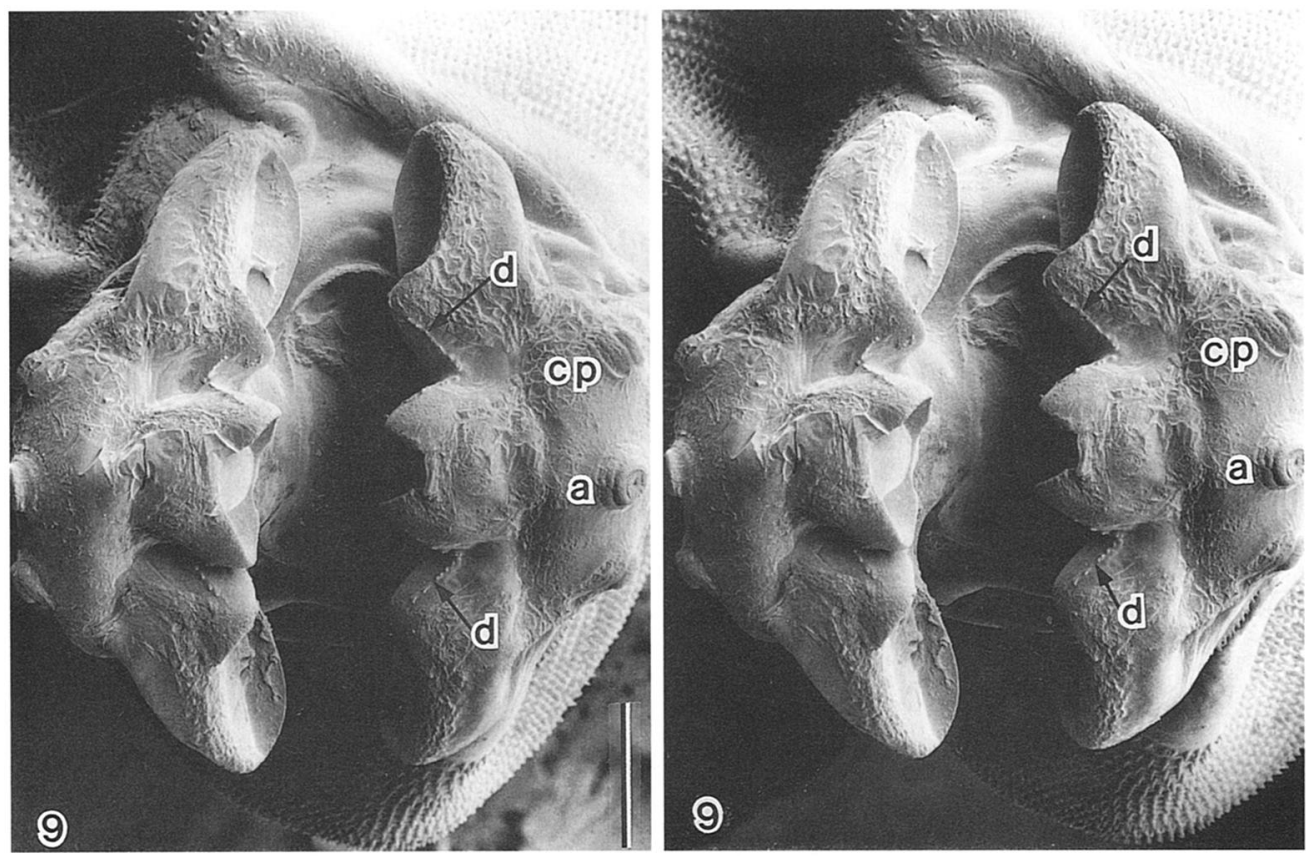

FIGURE 9. Echinocephalus janzeni $n$. sp., cephalic extremity of a male, en face view in stereo imagery with SEM; scale bar $=50 \mu \mathrm{m}$. Note the complex structure of the left and right pseudolabia, the prominent amphids (a), double cephalic papillae (cp), and dentigerous ridges (d).
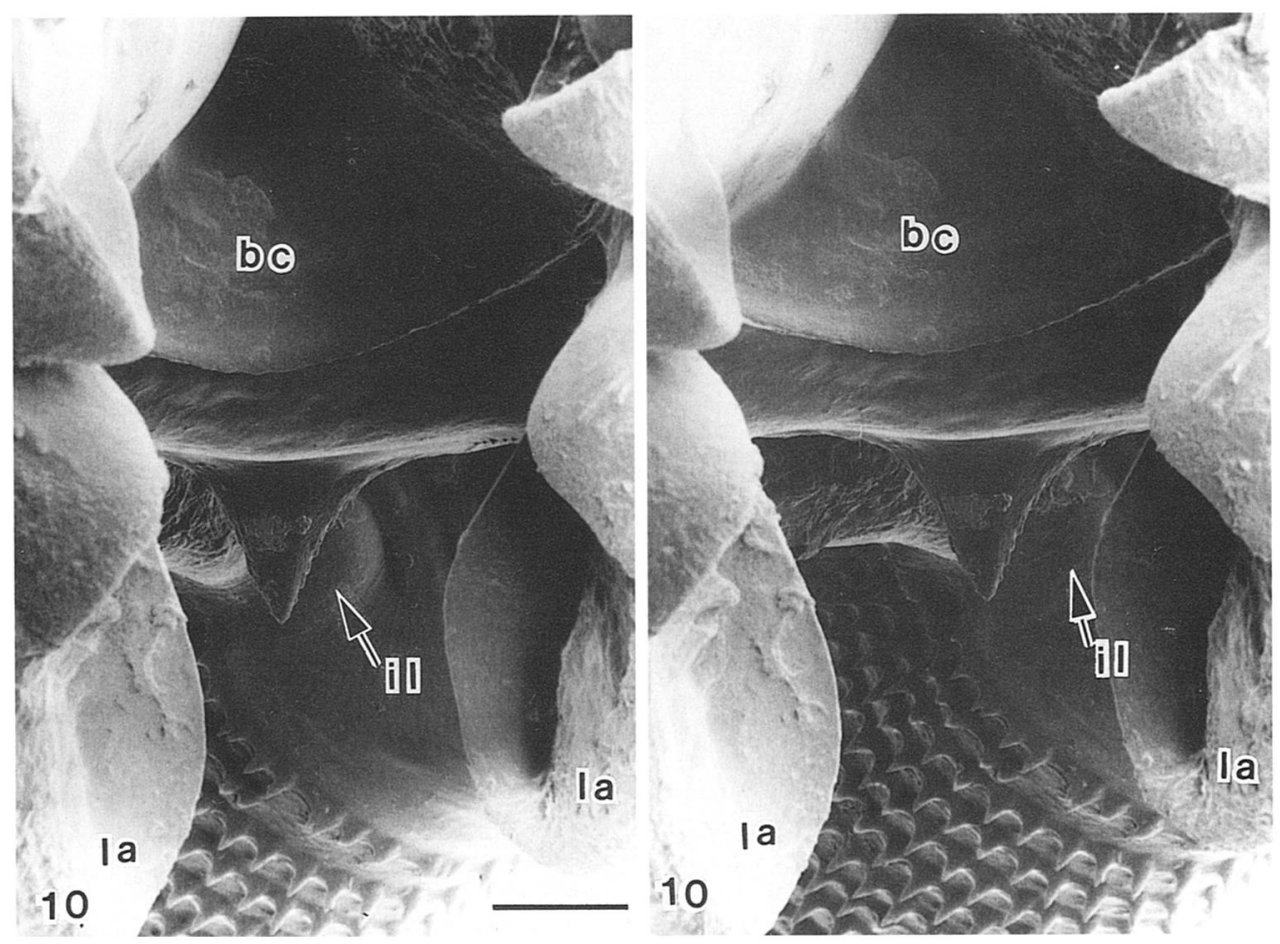

FIGURE 10. Echinocephalus janzeni $\mathrm{n}$. sp. Detail of cephalic extremity of a male, en face view in stereo imagery with SEM; scale bar $=15$ $\mu \mathrm{m}$. Note the positions of the pseudolabia (la), buccal cavity (bc), and the thornlike and serrated interlabium (il).

FIGURES 5-8. Echinocephalus janzeni n. sp., caudal structures in holotype male; scale bars in micrometers. 5. Caudal extremity, right lateral view showing structure of bilobate caudal alae, position of papillae, and the ventral distribution of modified annules anterior to the alae; note subequal spicules. 6. Caudal extremity, ventral view showing the disposition of caudal papillae, position and structure of the anus, and form of the bilobate alae. 7. Spicule tips, note hyaline point. 8. Gubernaculum, ventral view. 

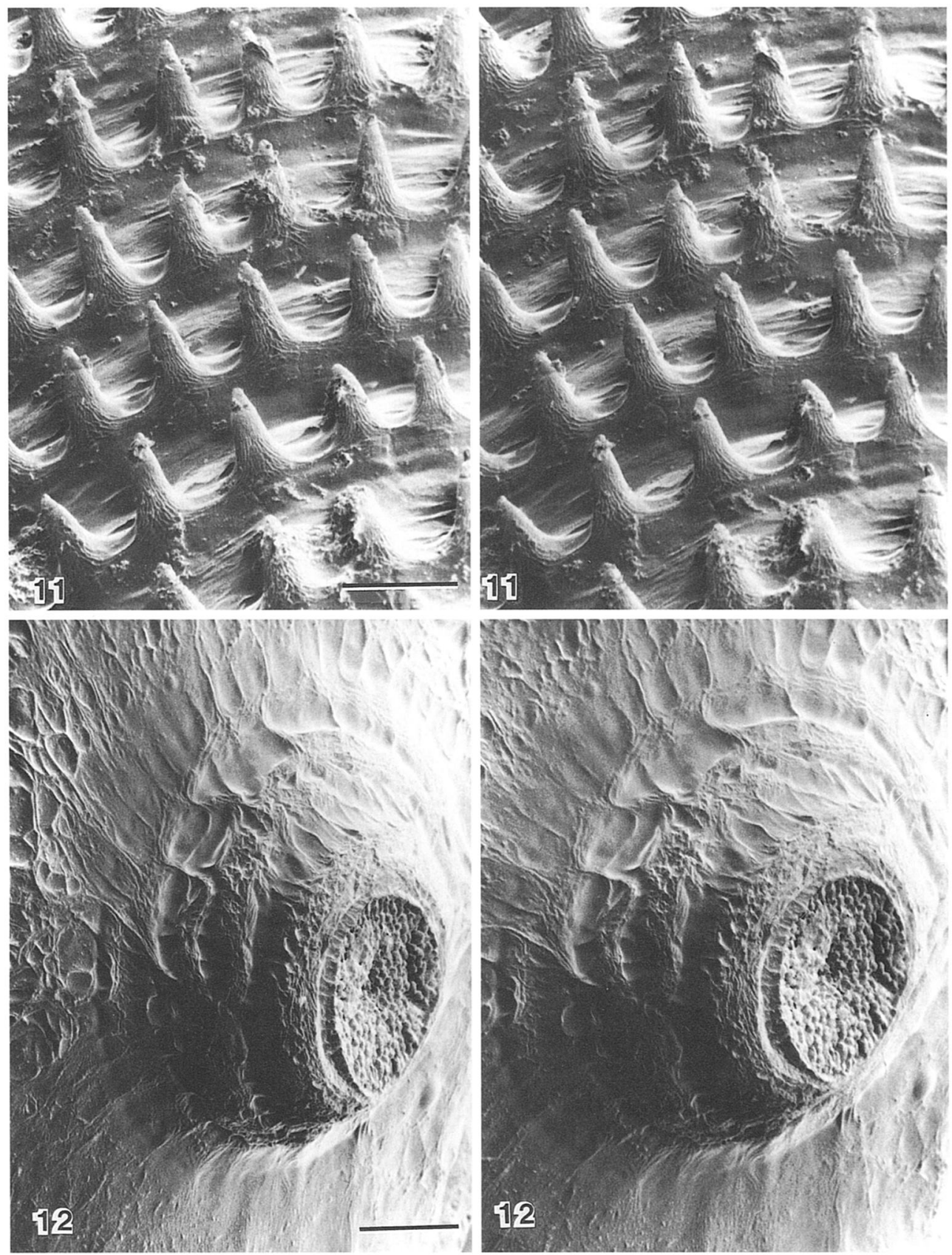

FIGURES 11, 12. Echinocephalus janzeni n. sp., cephalic structures of a male, in stereo imagery with SEM. 11. Pattern and structure of spines on midregion of cephalic bulb; scale bar $=5 \mu \mathrm{m}$. 12. Structure of amphid; scale bar $=5 \mu \mathrm{m}$.

$14-15 \%$ of body length, 3,500-3,952 long, $475-550$ wide at base; muscular region 500-598; glandular region 3,000-3,354; ratio of glandular to muscular regions $1: 0.17-0.18$. Vulva opening at $845-1,000$ from caudal extremity, $4-5 \%$ of total body length from posterior. Vagina vera 475-600, vagina uterina 1,200-3,050 long; total length of vagina $1,755-3,650$. Eggs, with smooth, thin shell, $(\mathrm{n}=50) 39-47(42 \pm 2.07)$ long, 23-31 (28 \pm 1.80$)$ wide. Distance from vulva to anus 395-460. Anus opening at $2 \%$ of body length from posterior. Digitiform tail, with cuticular fold near apex, 450-480 long, 160-200 in maximum width

\section{Taxonomic summary}

Host: Himantura pacifica (Beebe and Tee-Van).

Locality: Playa Panama, Guanacaste, Costa Rica (type) $\left(10^{\circ} 15^{\prime} \mathrm{N}\right.$, $\left.86^{\circ} \mathrm{O0} 0^{\prime} \mathrm{W}\right)$; also from near El Paredon, Chiapas, Mexico, in salt water off the mouth of the Mar Muerto lagoon (ca. $15^{\circ} 59^{\prime} \mathrm{N}, 94^{\circ} 00^{\prime} \mathrm{W}$ ).
Specimens: Holotype male (USNPC 87170) and allotype female (USNPC 87171) from type host and locality collected in June 1992 by D. R. Brooks and N. Lovejoy. Paratypes (USNPC 87172) include 4 additional males and 2 females from type host and locality. Vouchers include 8 males and 8 females from type host (4 males and 4 females, USNPC 87173; 4 males and 4 females, CNHe-UNAM 2642), collected by F. Marques from the alternate locality on 20 February 1997.

Habitat: Spiral intestine.

Etymology: The species is named in honor of Daniel Janzen in recognition of his commitment to biodiversity studies in the neotropics.

\section{Remarks}

Among the 9 currently recognized species, Echinocephalus janzeni n. sp. is most similar to $E$. daileyi and $E$. diazi on the basis of the presence of 6 postanal caudal papillae and the distribution of modified 

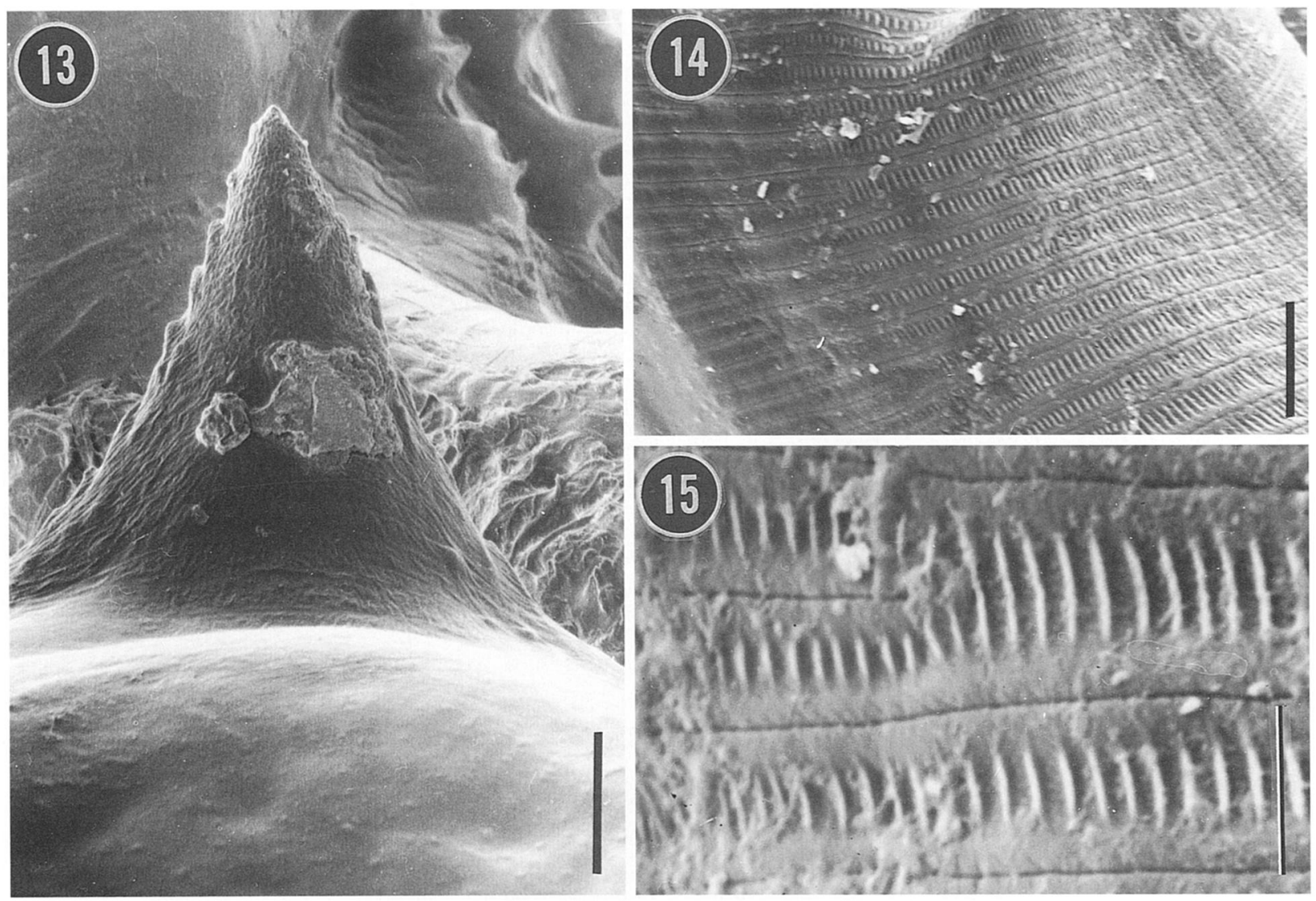

FIGURES 13-15. Echinocephalus janzeni n. sp., surface cuticular structures in SEM. 13. Interlabium from en face view, showing thornlike structure and prominent serrated margins; scale bar $=5 \mu \mathrm{m}$. 14. Caudal region of male, anterior to alae, showing pattern and distribution of modified ventral annules; scale bar $=30 \mu \mathrm{m}$. 15. Modified annules showing structure along anatomical right margin; scale bar $=10 \mu \mathrm{m}$.

annules anterior to the caudal alae in males (see Troncy, 1969; Deardorff et al., 1981). The numbers of postanal caudal papillae distinguish this group of Echinocephalus spp. from all other congeners. Specimens of $E$. janzeni are distinguished from those of $E$. daileyi by the relatively anterior demarcation of the muscular and glandular esophagus $(\leq 20 \%$ from anterior vs. near $50 \%$ in E. daileyi), long cervical sacs that extend up to $65 \%$ of the length of the esophagus ( $50 \%$ in E. daileyi), and the bilobed structure of the caudal alae. Although most similar to, and the putative sister species of, $E$. diazi on the basis of the analysis presented below, specimens of E. janzeni can be differentiated by a greater number of rows of cephalic spines (30-38 vs. 26-27), the arrangement of the postanal caudal papillae, 3 rather than 2 preanal papillae, relative position and distance between the anus and vulva (395-460 $\mu \mathrm{m}$ vs. 70 $\mu \mathrm{m})$, the digitiform female tail with a terminal cuticular fold, and the length of the female tail (450-480 $\mu \mathrm{m}$ vs. $270 \mu \mathrm{m})$ (see Troncy, 1969; Deardorff et al., 1981). Additionally, Troncy (1969) showed the cervical sacs to be $>50 \%$ of the length of the esophagus in E. diazi. Examination of 5 paratypes, however, showed them to be near midlength of the esophagus, thus those typical of $E$. janzeni are distinctly longer.

\section{Phylogenetic analysis}

One expectation of phylogenetic systematic studies is that the robustness of phylogenetic hypotheses should increase with increased sampling of characters and species. The present study offers an opportunity to test that assumption empirically. There have been 2 previous efforts to elucidate the phylogenetic relationships of members of Echinocephalus (see Deardorff et al., 1981; Brooks and Deardorff, 1988). This study permits us to update the phylogenetic tree for the genus once again on the basis of new information and additional characters for phylogenetic analysis.

(1) Gubernaculum. $0=$ absent; $1=$ present

(2) Number of preanal papillae. $0=3 ; 1=2$.
(3) Rugose patches around the male cloaca. $0=$ absent; $1=$ present. Examination of the type specimens of E. pseudouncinatus revealed the presence of rugose patches around the male cloaca previously reported only for E. sinensis, E. overstreeti, and E. uncinatus. Beveridge (1985) reported that Echinocephalus spinosissimus (Linstow, 1905) lacked rugose patches but depicted poorly defined cuticular modifications in the same position. This might be a precursor to the rugose patches, or a variation of them, but we are not certain so we have coded that species as uncertain (?) for the character.

(4) Orientation of oral and labial structures. $0=$ "normal" for spirurids (lips disposed laterally, mouth elongate dorsoventrally); 1 = lips exhibit torsion, oriented $90^{\circ}$ (lips disposed dorsoventrally, mouth elongate laterally). Comparison with other spirurid groups suggests that the condition found in E. overstreeti and $E$. daileyi is apomorphic. The dorsoventral orientation of the lips may be exceptionally rare among the gnathostomatids and other spirurids (see Chitwood and Wehr, 1934; Ko et al., 1980).

(5) Shape of caudal alae. $0=$ unilobed; $1=$ bilobed.

(6) Clustering of postanal papillae (clustering of papillae 4, 5, and 6). $0=$ not clustered; 1 = clustered.

(7) Number of pseudolabial teeth. $0=4 ; 1=6 ; 2=8-11$ (see Beveridge, 1985).

(8) Number of rows of spines on cephalic bulb. $0=$ mean number $<10$, typical of Gnathostoma spp.; $1=>10$, maximum 13; $2=\max$ imum 18;3 = maximum $21 ; 4=$ maximum $27-29 ; 5=$ maximum 30 $38 ; 6=$ maximum $40-43$. This is a putative synapomorphy for Echinocephalus because all species have $>10$ rows of cephalic spines. Additionally, the plesiomorphic condition of a low number of rows is corroborated by ontogenetic data, e.g., early stages of $E$. sinensis and $E$. pseudouncinatus according to Ko (1975) and Millemann (1963).

(9) Number of pairs of postanal papillae. $0=4 ; 1=5 ; 2=6 ; 3$ $=3$. 

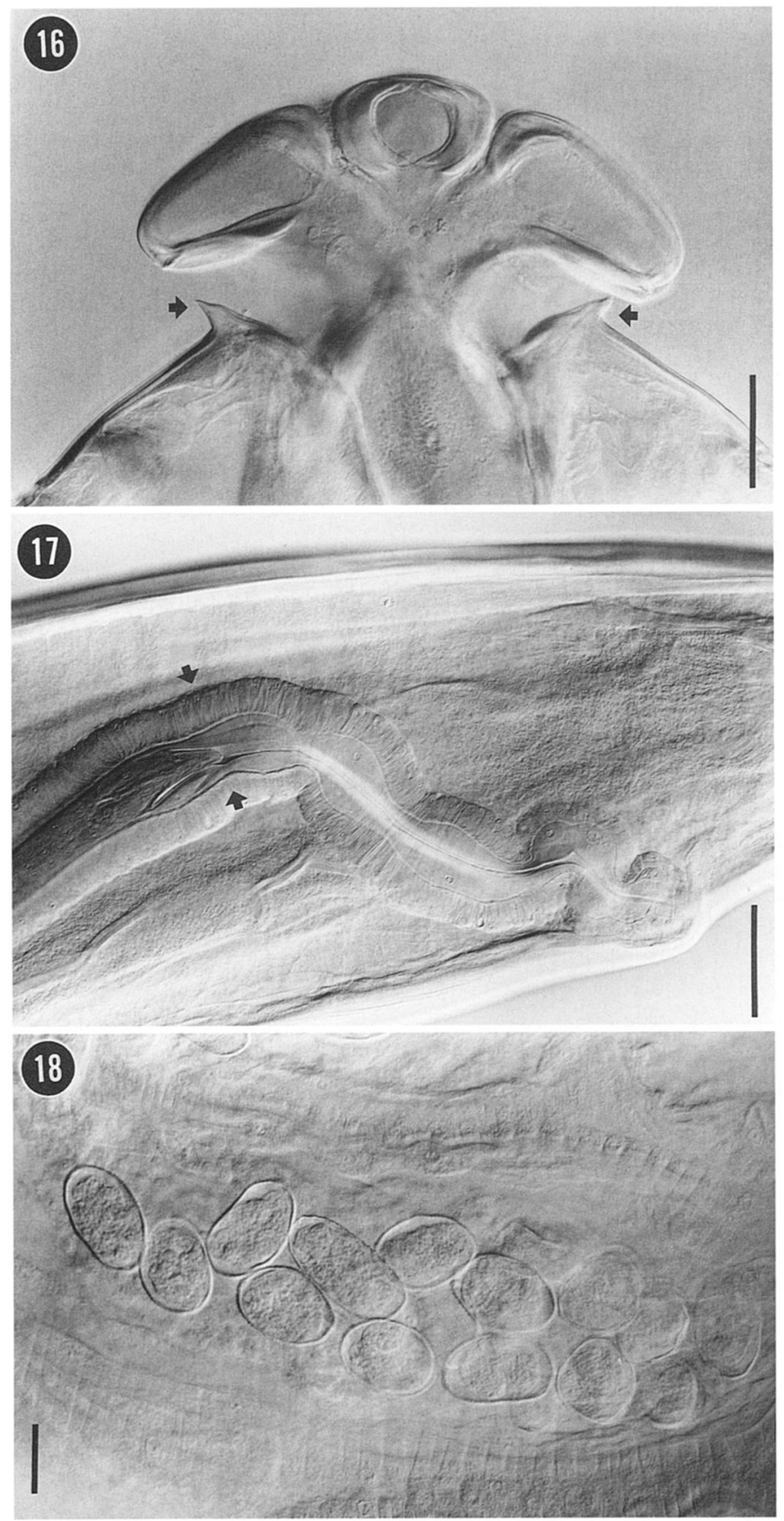

FIGURES 16-18. Echinocephalus janzeni n. sp., details revealed by interference contrast microscopy. 16. Cephalic region in allotype female showing cuticularized support of pseudolabia and prominent interlabia (arrows); scale bar $=50 \mu \mathrm{m}$. 17. Vulva showing structure of vagina vera and junction with vagina uterina (arrows); scale bar $=100 \mu \mathrm{m}$. 18. Eggs at level of uterine bifurcation anterior to sphincter in female; scale bar $=25 \mu \mathrm{m}$.

(10) Adanal papilla. $0=$ none present; $1=1$ pair present.

(11) Annules on ventral surface of tail modified. $0=$ lacking; $1=$ present.

(12) Interlabia. $0=$ present; 1 = absent. Data for E. multidentatus and $E$. southwelli are not available, and this character is coded as missing (?).

(13) Cervical sacs. The plesiomorphic condition in Echinocephalus was coded by functional outgroup criteria after preliminary analysis. 0
$=$ extending to near posterior extremity or base of the esophagus as in the basal taxa E. multidentatus Baylis and Lane, 1920, and E. southwelli Baylis and Lane, 1920 (according to Baylis and Lane, 1920); 1 = approximately $50 \%$ of total esophageal length; $2=$ approximately $40 \%$ of total esophageal length; $3=$ approximately $65 \%$ of total esophageal length.

(14) Relative length of the glandular to muscular esophagus. $0=$ ratio generally $\geq 1: 1$, at midlength; $1=$ ratio $\leq 1: 0.20$, substantially in anterior near nerve ring.

(15) Relative position of the vulva. $0=$ posterior to midbody in middle third, generally $>4 \mathrm{~mm}$ from apex of tail; $1=$ located far in posterior adjacent to tail, generally $<1 \mathrm{~mm}$ from tail. This is a putative synapomorphy for Echinocephalus.

Phylogenetic analysis of these 15 characters produced a single most parsimonious tree, with a consistency index of 0.893 ( 0.880 excluding uninformative characters) and retention index of 0.864 (Fig. 19). Monophyly for Echinocephalus is supported by 2 characters, number of rows of cephalic spines (char. 8) and position of the vulva (char. 15). The following relationships are recognized: E. southwelli is the basal taxon, and E. multidentatus is the sister species for the remaining members of the genus. Two higher clades sharing a sister-group relationship are depicted: 1 with $E$. daileyi and $E$. diazi $+E$. janzeni, and the other with $E$. spinosissimus $+E$. uncinatus as the sister group of E. overstreeti and E. pseudouncinatus + E. sinensis.

\section{DISCUSSION}

A revised phylogeny for the species of Echinocephalus allows reexamination of the historical biogeographic and coevolutionary relationships of these gnathostomatids and their hosts. Echinocephalus janzeni $\mathrm{n}$. sp. inhabits $H$. pacifica, which is the probable sister species of Himantura schmardae Werner (see Lovejoy, 1996) and the host of $E$. diazi; it is $E$. diazi that is the putative sister species of E. janzeni. According to Lovejoy (1996), H. schmardae $+H$. pacifica is the sister group of the Potamotrygonidae, the South American freshwater stingrays. In this new analysis, E. daileyi, which inhabits freshwater stingrays (species of Potamotrygon Garman), is the sister species of E. janzeni $+E$. diazi. If Echinocephalus is a reasonable indicator of historical coevolutionary relationships, the relationships among those 3 species support Lovejoy's (1996, 1997) contention. In order to assess the extent to which Echinocephalus should be seen as a good indicator of historical coevolutionary relationships, however, we must examine the host relationships of all the members of the genus.

Echinocephalus southwelli and E. multidentatus, the 2 basal members of the genus, inhabit Urogymnus asperrimus (Bloch and Schneider), a member of the Dasyatididae. Two other species also inhabit $U$. asperrimus. Echinocephalus spinosissimus was described originally in Myliobatus aquila (Linnaeus), a member of the Myliobatidae, but has also been reported in $U$. asperrimus as well as Himantura imbricata (Bloch and Schneider), both members of the Dasyatididae, and E. overstreeti was described in Taeniura melanopilos (Bleeker), another dasyatidid, and has also been reported in $U$. asperrimus. Echinocephalus uncinatus, the sister species of E. spinosissimus, has been reported in Dasyatis centroura (Mitchill) and Dasyatis pastinaca (Linnaeus), both dasyatidids. Finally, E. sinensis was described in Aetobatus flagellum (Bloch and Schneider) and $E$. pseudouncinatus in Myliobatis californicus Gill, both members of the Myliobatidae; E. pseudouncinatus has also been found in the shark Heterodontus francisci (Girard).

Phylogenetic optimization of host types indicates that the plesiomorphic host is Urogymnus Müller and Henle. The coevolutionary significance of this is uncertain because Lovejoy 


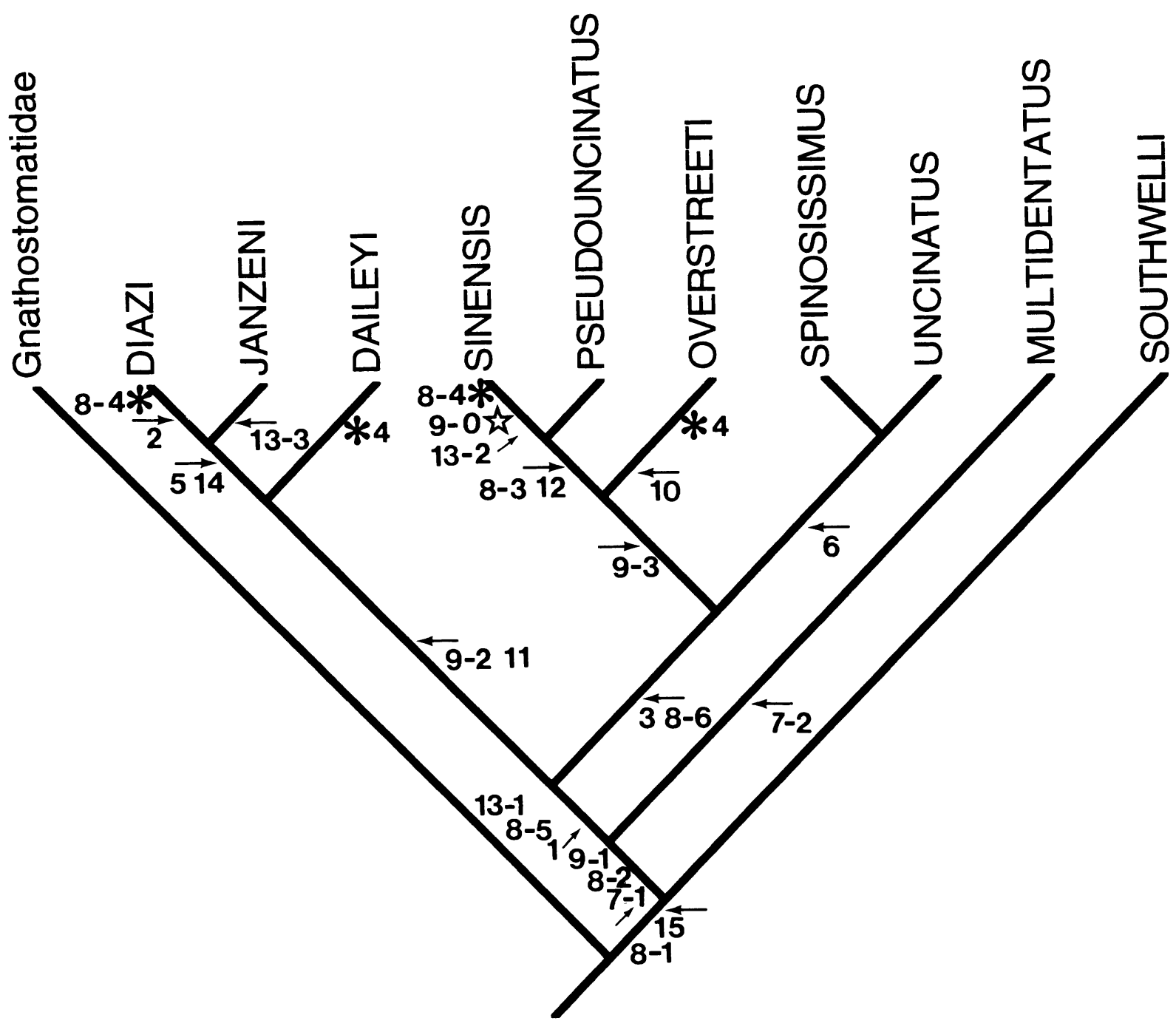

FIGURE 19. Phylogenetic hypothesis for species of Echinocephalus resulting from cladistic analysis of 15 characters derived from comparative morphology. Shown is the most parsimonious tree $(\mathrm{CI}=0.893$; minimum length $=25$; required steps $=28)$. Characters are mapped onto the tree, arrows indicate apomorphic characters, asterisks indicate putative homoplasy (parallelism or convergence); stars indicate reversal; numerical codes for characters are consistent with the matrix and descriptions in text (Table I). Transformations for multistate characters (chars. 7, 8, 9, and 13 ) are denoted by hyphenated numerals, with states being consistent with the matrix. Note the placement of $E$. diazi and $E$. janzeni as sister taxa and the definition of a subclade with $E$. daileyi. Biogeographic implications of this phylogeny are outlined in the text.

(1996) did not include Urogymnus in his analysis. If we make the assumption that Urogymnus is the sister group of all rays excluding the Urolophus Müller and Henle and the Urobatis Garman/Urotrygon Gill clades in Lovejoy's analysis, we can find marked agreement between the Echinocephalus tree and Lovejoy's hypothesis. Lovejoy proposed that the sister group of the Taeniura Müller and Henle + Potamotrygonidae $+\mathrm{H}$. pacificalH. schmardae clade was a clade containing the Myliobatidae (Gymnura Van Hasselt, Myliobatis Geoffroy, Aetobatus Blainville, Mobula Rafinesque, and Manta Bancroft) in a polytomy with an assemblage of some species in Dasyatis Rafinesque lacking any synapomorphy to support their monophyly and a clade of the rest of the members of Dasyatis plus the other members of Himantura Müller and Henle.

If we examine the clade that is the sister group to the $E$. dailey $i+E$. janzeni $+E$. diazi clade, we find the basal members are a clade including E. spinosissimus and E. uncinatus. Echinocephalus spinosissimus has been found in $H$. imbricata, and $E$. uncinatus has been found in 2 species of Dasyatis; if $D$. pastinaca and D. centroura are in Lovejoy's Dasyatis 1 group, this would be consistent. Echinocephalus spinosissimus, however, has also been found in $M$. aquila and $U$. asperrimus, which would be explained as host switches when we force maximum agreement between the Echinocephalus tree and Lovejoy's tree. The next species up the tree in that clade is $E$. overstreeti, which has been found in $U$. asperrimus and T. melanopilos. According to Lovejoy's tree, Taeniura is the sister species of Potamotrygonidae $+H$. pacifical $H$. schmardae. This would be best explained as at least 1 host switch. The sister group of E. overstreeti is E. sinensis $+E$. pseudouncinatus, both of which inhabit myliobatids, a relationship congruent with Lovejoy's hypothesis. As stated above, however, this interpretation is contingent on Urogymnus being the sister group of all dasyatid, potamotrygonid, and myliobatid stingrays. If Urogymnus is related in any other way to those stingrays, optimizing host types onto the nematode tree requires a minimum of 7 host 
switches. Thus, the extent to which Echinocephalus should be taken as an unambiguous indicator of historical coevolutionary relationships is uncertain. It is also relevant to note that Lovejoy's (1996) grouping of Taeniura + Potamotrygonidae $+H$. pacifica/H. schmardae is based on only a single synapomorphy, which is homoplasious on his tree. In addition, his postulated clade of $H$. pacifica $+H$. schmardae has no postulated synapomorphy at all.

Brooks (1979) suggested that parasites exhibited stronger historical associations with the areas in which they evolved and lived than with the particular species of hosts they inhabit. Subsequent phylogenetic systematic studies of parasite groups in which host and geographic relationships have been examined support this contention (see studies summarized in Brooks and McLennan, 1993). This appears to be the case with Echinocephalus. Although Echinocephalus does not resolve the sistergroup relationships of the potamotrygonids unambiguously, it does provide unambiguous support for the hypothesis that the ancestor of the potamotrygonids came from the Pacific Ocean, as suggested previously (Brooks et al., 1981; for a recent summary, see Brooks and McLennan, 1993). Echinocephalus diazi occurs in the Caribbean and its sister species occurs in the eastern Pacific Ocean. The sister species of those 2 is $E$. daileyi, living in Potamotrygon orbignyi (Castelnau), indicating an ancestral association between the eastern Pacific Ocean + Caribbean Sea and the Amazon basin. Lovejoy (1997) recently suggested that this association indicated that the freshwater stingrays could have invaded freshwater habitats from the Caribbean Sea rather than the Pacific Ocean as suggested by previous studies (summarized in Brooks, 1995). By examining the geographic distributions of all the members of the genus, it is clear that Lovejoy's postulate is not supported. The 2 basal members, $E$. southwelli and E. multidentatus, occur in the Indian Ocean (Sri Lanka). The remaining 8 species occur in 2 clades. One of these is the $E$. daileyi $+E$. janzeni $+E$. diazi clade, whose distribution pattern has already been discussed. The sister group comprises 5 species living primarily in the Pacific Ocean. Within it, E. spinosissimus from the Indian Ocean (Sri Lanka) and $E$. uncinatus from the Mediterranean region (Black Sea and Adriatic Sea) form a subclade that is the sister group of the other 3 species. Of that group, E. overstreeti from the western and central Pacific Ocean (Enewetak Atoll and the Marquesas Islands) is the sister species of $E$. sinensis from Hong Kong and E. pseudouncinatus from the northeastern Pacific. If, as Lovejoy has suggested, the potamotrygonids invaded freshwater from the Atlantic Basin, (1) we would expect $E$. uncinatus to be the sister species of $E$. daileyi $+E$. diazi $+E$. janzeni, (2) we would expect to find $E$. daileyi or close relatives living not only in the Amazon Basin but also in northern river systems, such as the Magdalena River of Colombia, where $H$. schmardae, host of $E$. diazi, lives, and (3) we would expect to find $E$. daileyi or close relatives living in Paratrygon Dumeril or Plesiotrygon Rosa, Castello, and Thorson or other members of Potamotrygon, rather than only in Potamotrygon orbignyi, the type host (host specificity data from F. Marques, pers. comm.). Consequently, the new phylogenetic tree for Echinocephalus may provide support for Lovejoy's hypothesis of stingray relationships, but it does not provide evidence for an Atlantic basin origin of the potamotrygonids; rather, it supports strongly the Pacific origins hypothesis of Brooks and coworkers.

\section{ACKNOWLEDGMENTS}

Some specimens of Echinocephalus spp. were made available from the Muséum National D'Histoire Naturelle, Paris, by Jean-Pierre Hugot. Specimens of E. janzeni from Chiapas, Mexico, were collected and made available for this study by Fernando Marques, Department of Zoology, University of Toronto.

\section{LITERATURE CITED}

Baylis, H. A., AND C. LANE. 1920. A revision of the nematode family Gnathostomidae. Proceedings of the Zoological Society of London, Sept., 245-310.

BEVERIDGE, I. 1985. A redescription of Echinocephalus uncinatus Molin, 1858 (Nematoda: Gnathostomatoidea) from european rays, Dasyatis pastinaca (Linnaeus, 1758). Bulletin du Museum National d'Histoire Naturelle, Paris 4: 781-790.

Brooks, D. R. 1979. Testing the context and extent of host-parasite coevolution. Systematic Zoology 28: 299-307.

1995. Neotropical freshwater stingrays and their parasites: A tale of an ocean and a river long ago. Journal of Aquariculture and Aquatic Science 7: 52-61.

- AND T. L. DEARDORFF. 1988. Rhinebothrium devaneyi n. sp. (Eucestoda: Tetraphyllidea) and Echinocephalus overstreeti Deardorff and Ko, 1983 (Nematoda: Gnathostomatidae) in a thorny back ray, Urogymnus asperrimus, from Enewetak Atoll, with phylogenetic analysis of both species groups. Journal of Parasitology 74: 459-465

, AND D. A. MCLEnNAN. 1993. Parascript, parasites and the language of evolution. Smithsonian Institution Press, Washington, D.C., 429 p.

, T. B. Thorson, And M. A. MAyes. 1981. Fresh-water stingrays (Potamotrygonidae) and their helminth parasites: Testing hypotheses of evolution and coevolution. In Advances in cladistics: Proceedings of the first meeting of the Willi Hennig Society, V. A. Funk and D. R. Brooks (eds.). New York Botanical Garden, New York, New York, p. 147-175.

Chitwood, B. G., AND E. E. WeHR. 1934. The values of cephalic structures as characters in nematode classification, with special reference to the superfamily Spiruroidea. Zeitschrift für Parasitenkunde 7: 273-335.

DeardorfF, T. L., D. R. Brooks, and T. B. Thorson. 1981. A new species of Echinocephalus (Nematoda: Gnathostomidae) from neotropical stingrays with comments on $E$. diazi. Journal of Parasitology 67: 433-439.

- AND R. C. KO. 1983. Echinocephalus overstreeti sp. n. (Nematoda: Gnathostomatidae) in the stingray, Taeniura melanopilos Bleeker, from the Marquesas Islands, with comments on E. sinensis Ko, 1975. Proceedings of the Helminthological Society of Washington 50: 285-293.

HenNIG, W. 1950. Grundzüge einer Theory der phylogenetischen Systematik. Deutscher Zentralverlag, Berlin, Germany, 370 p.

. 1966. Phylogenetic systematics. University of Illinois Press, Urbana, Illinois, $263 \mathrm{p}$.

Ko, R. C. 1975. Echinocephalus sinensis n. sp. (Nematoda: Gnathostomatidae) from the ray (Aetabatus flagellum) in Hong Kong, southern China. Canadian Journal of Zoology 53: 490-500.

- 1976. Experimental infection of mammals with larval Echinocephalus sinensis (Nematoda: Gnathostomatidae) from oysters (Crassostrea gigas). Canadian Journal of Zoology 54: 597-609.

- J. LING, AND M. N. ADAL. 1980. Cephalic anatomy of a gnathostomatid nematode Echinocephalus sinensis, a parasite of oysters and rays. Journal of Morphology 165: 301-317.

- , B. MORTON, AND P. S. WONG. 1975. Prevalence and histopathology of Echinocephalus sinensis (Nematoda: Gnathostomatidae) in natural and experimental hosts. Canadian Journal of Zoology 53: 550-559.

LOVEJOY, N. R. 1996. Systematics of myliobatoid elasmobranchs: With emphasis on the phylogeny and biogeography of neotropical fresh- 
water stingrays (Potamotrygonidae). Zoological Journal of the Linnaean Society 117: 207-257.

- 1997. Stingrays, parasites, and neotropical biogeography: A closer look at Brooks et al.'s hypothesis concerning the origins of neotropical freshwater rays (Potamotrygonidae). Systematic Biology 46: $218-230$.

Maddison, W. P., M. J. Donoghue, and D. R. Maddison. 1984. Outgroup analysis and parsimony. Systematic Zoology 33: 83-103.

MillemanN, R. E. 1951. Echinocephalus pseudouncinatus $\mathrm{n}$. sp., a nematode parasite of abalone. Journal of Parasitology 37: 435-439.

. 1963. Studies on the taxonomy and life history of echinocephalid worms (Nematoda: Spiruroidea) with a complete description of Echinocephalus pseudouncinatus Millemann, 1951. Journal of Parasitology 49: 754-764.
MIYAZAKI, I. 1960. On the genus Gnathostoma and human gnathostomiasis, with special reference to Japan. Experimental Parasitology 9: 338-370.

SwOFFORD, D. L. 1993. PAUP: Phylogenetic analysis using parsimony, version 3.1.1. Computer program distributed by Illinois Natural History Survey, Champaign, Illinois.

TronCY, P.-M. 1969. Description de deux nouvelles espèces de nèmatodes parasites de poissons. Bulletin du Museum National d'Histoire Naturelle 41: 598-605.

Watrous L. E., AND Q. D. WheELER. 1981. The out-group comparison method of character analysis. Systematic Zoology 30: 1-11.

Wiley, E. O., D. Siegel-Causey, D. R. Brooks, and V. A. Funk. 1991. The compleat cladist, a primer of phylogenetic procedures. Special Publication 19. University of Kansas Museum of Natural History, Lawrence, Kansas, 158 p. 